\title{
The continuing barriers to research in China
}

\author{
Jin-Ling Tang MD PhD
}

Previously published at www.cmaj.ca

$\infty \infty$

See related research article by Liu and colleagues, page 439

I n January 2008, the formula for Sanlu infant milk and its related technology received the National Award for Science and Technology Progress, one of the most prestigious awards for science and technology in China. Later that year, Sanlu infant milk products were found to contain melamine, which can cause urinary tract abnormalities.

Liu and colleagues assessed the prevalence of urinary tract abnormalities in Chinese children living in rural areas who were exposed to dairy products contaminated with melamine. ${ }^{1}$ Although China now benefits increasingly from its scientific research and technologic development, the incident with Sanlu infant milk formula highlights some of the barriers to research in that country - the way research funding is allocated; the way researchers are rewarded; the negative image of Chinese research following isolated but publicized episodes of deceit; the limited language skills of researchers; the money researchers make; and, to some extent, the way medical students are taught.

Researchers are evaluated, compared and rewarded primarily according to local (versus international) standards and by surrogate measures, such as the amount of grant money they obtain ${ }^{2}$ - though this is not unique to China. The amount of research funding received, however, may not match the quality of the scientific output. Furthermore, allocation of funding is sometimes influenced by connections, administrative status and political influence. Therefore, adopting local standards for evaluation and comparison only encourages competition for funding rather than achieving the objective of the funding. It makes funds become an end in themselves, rather than promoting research excellence.

The way research funding is allocated and projects are evaluated and funded in China does not seem to promote innovative research. ${ }^{3,4} \mathrm{~A}$ large portion of the limited funds available is spent on a few mega-projects; these projects are often conceived and planned by consensus among administrators and scientists who set short deadlines for completion and influence the decision on successful applications. ${ }^{3,5}$ History shows that the most innovative ideas in science are often not planned by committees and consensus - they come through almost at random from individual scientists. It is difficult to predict which scientist and which project will be successful. Setting short and unrealistic deadlines can be counterproductive. It is likely to encourage short-term and poorly developed research. Sometimes there is a lack of clarity about how conflict of interest can be handled effectively when referees are

\section{Key points \\ - China has made considerable progress in promoting scientific research in the past decades. \\ - A major obstacle to research in China is the way researchers are evaluated, compared and rewarded. \\ - China will make a greater contribution to science if its researchers are encouraged to take part in the global competition by publishing more research internationally.}

competing for the same funding. As a result, the truly innovative ideas and most deserving researchers may not be funded. Furthermore, when research funding is linked to a personal financial reward, the rewarding of grant money may create nonacademic incentives for securing funding.

Scientists in China commonly are rewarded with prizes and awards, ${ }^{6}$ which are offered at almost every level by national, ministerial, provincial and municipal administration and by universities and schools. Researchers are often promoted according to the prestige and the number of awards they have won, and the best promotions are those that put the researcher in an administrative position, such as head of a department, a dean, a university president or a high-ranking position in government. Indeed, over $80 \%$ of newly elected fellows of the Chinese Academy of Sciences and the Chinese Academy of Engineering are high-level administrators of universities and national research institutions. ${ }^{7}$ A common concern is that these leading scientists, once they are appointed to administrative positions, may not have enough time to think about research and thus waste their talent as researchers. ${ }^{8}$

It is difficult to assess the importance and reliability of a piece of research soon after its completion. Giving away prizes too quickly may result in mistakes, as in the case of Sanlu infant milk.

The system of assessing and rewarding research only within a local area (e.g., a city or country) tends to encourage scientists to perform "me-too" research and to be the "first in that place" to do something that has been done elsewhere. Such a system does not encourage scientists to compete internationally, to have their work published in international jour-

From the School of Public Health and Primary Care, The Chinese University of Hong Kong, Hong Kong, China

CMAJ 2010. DOI:10.1503/cmaj.100035

All editorial matter in CMAJ represents the opinions of the authors and not necessarily those of the Canadian Medical Association. 
nals so it can be reviewed and tested by their peers worldwide. The consequence is that China is unlikely to produce internationally recognized science and scientists without such international participation.

The image of China has been tarnished in the minds of some of the international scientific community following isolated but well-publicized episodes of deceit, as in the case of infant milk contaminated with melamine and following the recent retraction of several fraudulent publications in chemistry. ${ }^{9}$ Research from China that does reach an international audience is often about health crises, such as epidemics caused by severe acute respiratory syndrome and H5N1 influenza virus, which contributes to the country's negative image.

Lack of ability to write well in English is another significant barrier faced by Chinese researchers. Editors, especially of journals with small editorial teams, are unlikely to have much patience with papers submitted in poor English. Published studies from China may be of lower quality (e.g., in methodology $)^{10}$ than those submitted from other countries. Editors may reject important papers out of a fear of research misconduct and dishonesty or because they believe that the articles will not attract sufficient citation.

Compared with developed countries, China spends a much smaller percentage of its gross domestic product $(1.58 \%$ in 2009) on scientific research. ${ }^{4}$ Although this may change as the economy grows in China, the notion of becoming an academic or a researcher has become much less attractive than it was 20 years ago. Indeed, much talent has drifted from research to business, management, administration, banking and finance, where people are better paid. Now, even within medicine, more people choose to become practising physicians, a more lucrative profession, than researchers. Even if some people are interested in becoming researchers, the education system and culture in most universities in China tend not to encourage critical and creative thinking in students. ${ }^{4}$

These barriers are by no means unique to China, but China aspires to make positive changes. Although China now pub- lishes as many scientific papers each year as the United States, ${ }^{4}$ Chinese scientists are under-represented at the highest level of scientific publication. This can change once the barriers are tackled.

Competing interests: None declared.

Acknowledgements: The author thanks Dr. Bill Summerskill, Professor Sian Griffiths, Professor Wu Tangchun and Professor Lv Jun for sharing their thoughts and information.

\section{REFERENCES}

1. Liu J, Ren A, Yang L, et al. Urinary tract abnormalities in Chinese rural children who consumed melamine-contaminated dairy products: a population-based screening and follow-up study. CMAJ 2010 Feb. 22 [Epub ahead of print].

2. Jiang GM. Scientists should shake off the shackles of SCI and funding money [Chinese]. Science Net 2008 Jan. 27. Available: www.sciencenet.cn/htmlnews/2008127224254832200385.html (accessed 2009 Dec. 29).

3. Hennig W. Research in China. Experience from 23 years of molecular genetic research in Shanghai. EMBO Rep 2009; 10:545-50.

4. Wu R. Making an impact: compared with researchers in the United States, Chinese scientists publish far fewer highly cited papers. Nature 2004;428:206-7.

5. Xin H, Yidong G. Research funding. China bets big on big science. Science 2006;311:1548-9.

6. Yan GC. Rethinking China's academic reward system and its effects. [Chinese]. Science Times 2005 Mar. 1. Available: www.acriticism.com/article.asp?Newsid=6134 \&type $=1010$ (accessed 2009 Dec. 29).

7. Wang J, Lin Y. The new houses are mostly academicians officials accused of "acting as both player and referee" [Chinese]. China News Net 2009 Dec. 23. Available: www.chinanews.com.cn/edu/news/2009/12-23/2034006.shtml (accessed 2009 Dec. 29).

8. Zhang XT. When would academicians return to academic work: some thoughts about the fellowship of the Chinese Academy of Sciences [Chinese]. News Week. Available: http://learning.sohu.com/75/51/article213575175.shtml (accessed 2009 Dec. 29).

9. Harrison WTA, Simpson J, Weil M. Editorial. Acta Crystallogr 2010;E66:e1-2 10 .1107/S1600536809051757. Available at: www.sciencenet.cn/upload/blog/file /2009/12/20091224133550768633.pdf (accessed 2009 Dec. 29).

10. Tang JL, Zhan SY, Ernst E. Review of randomised controlled trials of traditional Chinese medicine. BMJ 1999;319:160-1.

Correspondence to: Dr. Jin-Ling Tang, Professor and Associate Director, School of Public Health and Primary Care, Faculty of Medicine, the Chinese University of Hong Kong, Prince of Wales Hospital, 30-32 Ngan Shing St., Shatin, New Territories, Hong Kong; jltang@cuhk.edu.hk 